Utah State University

DigitalCommons@USU

\title{
Games Governments Play: An Analysis of National Environmental Policy in an Open Economy
}

Amitrajeet A. Batabyal

Utah State University

Follow this and additional works at: https://digitalcommons.usu.edu/eri

\section{Recommended Citation}

Batabyal, Amitrajeet A., "Games Governments Play: An Analysis of National Environmental Policy in an Open Economy" (1999). Economic Research Institute Study Papers. Paper 168.

https://digitalcommons.usu.edu/eri/168

This Article is brought to you for free and open access by the Economics and Finance at DigitalCommons@USU. It has been accepted for inclusion in Economic Research Institute Study Papers by an authorized administrator of DigitalCommons@USU. For more information, please contact digitalcommons@usu.edu.

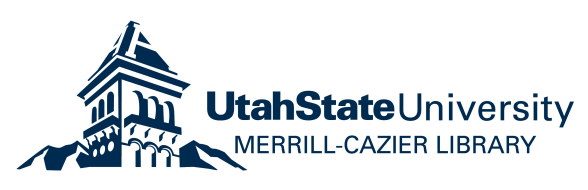


Economic Research Institute Study Paper

ERI \#99-18

\title{
GAMES GOVERNMENTS PLAY: AN ANALYSIS \\ OF NATIONAL ENVIRONMENTAL POLICY \\ IN AN OPEN ECONOMY
}

\author{
by \\ AMITRAJEET A. BATABYAL \\ Department of Economics \\ Utah State University \\ 3530 Old Main Hill \\ Logan, UT 84322-3530
}

May 1999 


\title{
GAMES GOVERNMENTS PLAY: AN ANALYSIS \\ OF NATIONAL ENVIRONMENTAL POLICY \\ IN AN OPEN ECONOMY
}

\author{
Amitrajeet A. Batabyal, Associate Professor \\ Department of Economics \\ Utah State University \\ 3530 Old Main Hill \\ Logan, UT 84322-3530
}

The analyses and views reported in this paper are those of the author(s). They are not necessarily endorsed by the Department of Economics or by Utah State University.

Utah State University is committed to the policy that all persons shall have equal access to its programs and employment without regard to race, color, creed, religion, national origin, sex, age, marital status, disability, public assistance status, veteran status, or sexual orientation.

Information on other titles in this series may be obtained from: Department of Economics, Utah State University, 3530 Old Main Hill, Logan, Utah 84322-3530.

Copyright (C) 1999 by Amitrajeet A. Batabyal. All rights reserved. Readers may make verbatim copies of this document for noncommercial purposes by any means, provided that this copyright notice appears on all such copies. 


\title{
GAMES GOVERNMENTS PLAY: AN ANALYSIS \\ OF NATIONAL ENVIRONMENTAL POLICY \\ IN AN OPEN ECONOMY
}

\section{Amitrajeet A. Batabyal}

\begin{abstract}
In this paper we study some of the consequences of national environmental policy in a strategic international setting. Two broad questions are analyzed. First, we examine the circumstances under which the pursuit of environmental policy by a country in a Cournot game, will make that country worse off when the incidence of pollution is domestic. Second, we study the effects of environmental regulation by means of alternate price control instruments in a Cournot game in which national governments care about international pollution, but polluting firms do not.

It is shown that there are plausible theoretical circumstances in which the pursuit of environmental policy in a strategic setting is not necessarily a desirable objective. Further, it is shown that in choosing between alternate pollution control instruments, national governments typically face a tradeoff between instruments which correct more distortions but are costly to implement and instruments which correct fewer distortions and are less costly to implement. In particular, a dominance result for a tariff policy is obtained; this result favors protection, i.e., the use of tariffs, from an informational standpoint alone.

JEL classification: D62, F13, Q28
\end{abstract}

Key words: Environmental policy, Cournot game, government, trade 


\section{GAMES GOVERNMENTS PLAY: AN ANALYSIS OF NATIONAL ENVIRONMENTAL POLICY IN AN OPEN ECONOMY ${ }^{1}$}

\section{Introduction}

Few issues have evoked as much debate in recent times as has the conduct of national environmental policy in an open economy. The greening of public consciousness across the world has forced governments to act on - hitherto relatively insignificant - environmental issues. At the same time, there has been a concerted attempt by business and industry to scale down the implementation of regulatory action designed to mitigate the damage stemming from environmental externalities. The fact that the conduct of environmental policy might affect trade flows between nations has added additional spice to the ongoing debate. ${ }^{2}$ Indeed as Leidy and Hoekman (1994, p. 241) have observed, “...there has been a dramatic rise in instances of sector-specific administered protection from foreign competition."

Given this situation, in this paper we study some aspects of the question of international environmental regulation from a game theoretic perspective. Two broad questions are addressed. We first examine the circumstances in which environmental policy, pursued strategically by a country in a Cournot game, will make that country worse off when the incidence of pollution is domestic. Second, we study the effects of regulating environmental pollution via alternate means in a Cournot game in which national governments are affected by international pollution, but polluting firms within nations are not. Put differently, this latter issue involves the analysis of a kind of caring

\footnotetext{
${ }^{1}$ I thank Larry Karp, John Kim, and anonymous referees for their input; I alone am responsible for the output. This research was supported by (i) the Giannini Foundation and by (ii) the Utah Agricultural Experiment Station, Utah State University, Logan, UT 84322-4810, by way of project UTA 024. Approved as journal paper no. 4873.

${ }^{2}$ See Morkre and Kruth (1989) for some of the issues involved.
} 
behavior by the respective national governments. ${ }^{3}$

The rest of this paper is organized as follows. In section 2, the pertinent literature relating to the questions to be addressed in this paper is reviewed. In section 3, we discuss the effects of strategic environmental policy when the incidence of pollution is domestic. In section 4, caring behavior by national governments is analyzed. In this setting, we shall be particularly interested in analyzing the efficacy of pollution control via alternate instruments. The three instruments that we shall consider are an import tariff (a trade policy instrument), a production tax (a domestic policy instrument), and a combination of these two instruments (the joint policy instrument). In section 5, the principal findings of this paper are summarized.

\section{International Environmental Regulation: A Synopsis of Findings}

Pethig (1976) and Asako (1979) have both shown that under certain conditions, when a nation's pollution intensive good is exported, increased trade can diminish that country's welfare. Siebert, Eichberger, Gronych, and Pethig (1980) have examined the relationship between environmental quality, environmental policy, and international trade in a two country world in some detail. In a non-strategic context, these authors have identified conditions for (i) an increase in resource use in pollution abatement and (ii) a fall in national income in the pollution controlling country.

Batabyal $(1991,1993)$ has studied the conditions under which environmental policy, pursued unilaterally by a large country will make that country worse off. These two papers contain results regarding the effects of environmental policy on (i) the post-policy terms of trade, (ii) the post-policy

\footnotetext{
${ }^{3}$ One can also think of this phenomenon as a kind of transboundary pollution.
} 
producer $^{4}$ price ratio in the taxing country, and on (iii) the effect of the pollution tax on "environmentally adjusted" national income in the taxing country.

Collectively, the clear message of these papers is that plausible theoretical circumstances exist in which the unilateral conduct of environmental policy by a large country - in a non-strategic context - can make that country worse off.

A number of authors have analyzed the question of international pollution control. Markusen (1975) has derived optimal taxes for pollution control when the incidence of pollution is international. However, his analysis is conducted in a static, competitive framework and hence this analysis does not address the important issues of imperfect competition, and possible caring government behavior. Merrifield (1988) has studied transboundary pollution control in the context of the USA-Canada acid deposition issue. Merrifield's analysis is static and conducted in a competitive framework. Consequently, his analysis does not take into account the strategic aspects of the USA-Canada acid deposition issue. Dockner and Long (1993) have studied the transboundary pollution control problem by formulating the problem as a differential game between two countries. Interestingly, they show that under certain circumstances, cooperative pollution control policies can be supported without recourse to retaliation.

Finally, the choice of alternate price control instruments has been little studied. Recently, a small number of researchers have begun to address this question theoretically and empirically. Ulph (1992) has shown that when international trade is modeled as a Cournot game, the choice of standards dominates the choice of taxes. Conrad and Schroder (1991) have studied the resource costs

\footnotetext{
${ }^{4} \mathrm{Here}$, producer refers to the producer of the polluting good.
} 
of attaining a given level of environmental quality by means of emission standards, subsidies and emission taxes in an applied general equilibrium model. They have shown that the use of an emission tax involves the lowest resource cost, followed by subsidies and then by emission standards.

None of these authors has modeled the fact that in an international dispute, governments typically pay considerable attention to the actions of other governments. ${ }^{5}$ In other words, governments recognize that the behavior of other governments matters and hence they care about such behavior. While this fact is quite well understood, it is rarely modeled. Even less modeled is the question of the effects of alternate price control instruments when national governments display this kind of caring behavior. As a result, a key objective of this paper is to study the pros and cons of alternate price control instruments in a Cournot game in which national governments display such caring behavior. ${ }^{6}$ We now proceed to the main analysis of this paper.

\section{The Game Model with Domestic Pollution}

\section{3a. Preliminaries}

There are two countries, $A$ and $B$. In each country there is a government which chooses a tax to control pollution, a monopolistic firm which produces a good for domestic and foreign consumption, and consumers who are affected by pollution differently and who buy on the domestic market from the $A$ firm or the $B$ firm. Further, there is a single good whose production causes pollution. This good will be denoted by $q$ with the appropriate superscripts. The total quantity of the good in $A$ is $Q^{A}=q^{A H}+q^{B X}$, where $q^{A H}$ and $q^{B X}$ denote the quantity produced by the $A$ firm

\footnotetext{
${ }^{5}$ See Behr (1994), and Simone (1994) for more on this in the context of USA-Canada agricultural trade disputes.

${ }^{6}$ For an analysis of similar questions in the context of a Stackelberg game, see Batabyal (1996a).
} 
for home consumption and the quantity exported by the $B$ firm. We shall denote the pollution taxes by $t^{A}$ and $t^{B}$ respectively. Observe that the two countries are identical on the production side. The only difference between them - on which more later - arises from the unequal marginal social disutilities from pollution.

In this paper we shall work with linear functional forms. As we shall see, even with the imposition of this additional structure, unambiguous results will in general not be forthcoming. Most of the results are in the form of inequalities. In certain cases, these inequalities can be easily understood; in other cases, the inequalities are harder to interpret.

Recall that the $A$ government levies a pollution tax on the production of the polluting good $q$. The $B$ government is allowed to retaliate. $B$ retaliates due to two reasons. First, although there is pollution in $B$ and $B$ would like to control pollution, $B$ is reluctant to take measures to do so unilaterally. $A^{\prime} s$ actions give $B$ a rationale for pollution prevention. Second, $B$ retaliates because $B$ fears that by allowing $A^{\prime} s$ actions to go unchallenged, $B$ will be worse off from the perceived shift in the terms of trade in $A^{\prime} s$ favor subsequent to the imposition of a pollution tax by $A .{ }^{7}$ Our goal is to characterize the optimal taxes and to explore the implications of using such taxes in the subgame perfect Nash equilibrium (SPNE) of a two stage Cournot game.

\section{3b. The Regulation of Domestic Pollution}

The total quantity of the good in $A$ is $Q^{A}=q^{A H}+q^{B X}$, where $q^{A H}$ is the quantity produced by the monopolistic $A$ firm for home consumption and $q^{B X}$ is the quantity exported by the monopolistic $B$ firm. In $B$, the total quantity on the market is $Q^{B}=q^{B H}+q^{A X}$. The market clearing

\footnotetext{
${ }^{7}$ Batabyal $(1991,1993)$ has shown that in some circumstances, these concerns are legitimate.
} 
price in $A$ and $B$ is $P^{A}=a-Q^{A}$, and $P^{B}=a-Q^{B}$, respectively. The $A$ and $B$ firms have two kinds of costs; the cost of producing the good and the cost associated with tax payment. The first cost for the $A$ firm is $C^{A}(\bullet)=c\left(q^{A H}+q^{A X}\right)$, where $c$ is the constant marginal cost. The second cost for the $A$ firm is $t^{A}\left(q^{A H}+q^{A X}\right)$. The government collects this second cost as tax revenue. This revenue is then transferred to consumers in $A$ in a lump sum manner. The $B$ firm has a similar cost structure. The social welfare function in each country is $W^{i}(\bullet)=(1 / 2)\left(Q^{i}\right)^{2}+\pi^{i}(\bullet)+t^{i}\left(q^{i H}+q^{i X}\right)-v^{i}\left(q^{i H}+q^{i X}\right), i=A, B$, where $\pi^{A}(\bullet)=\left\{q^{A H}\left(a-q^{A H}-q^{B X}-c-t^{A}\right)\right\}+\left\{q^{A X}\left(a-q^{A X}-q^{B H}-c-t^{A}\right)\right\}$ is the profit function of the $A$ firm, $\pi^{B}(\bullet)=\left\{q^{B H}\left(a-q^{B H}-q^{A X}-c-t^{B}\right)\right\}+\left\{q^{B X}\left(a-q^{B X}-q^{A H}-c-t^{B}\right)\right\}$ is the profit function of the $B$ firm and $v^{i}$ is the national disutility from pollution parameter. In other words, social welfare is the sum of consumer surplus, firm profits, tax revenue less the disutility from pollution, all measured in dollar terms.

The timing of the Cournot game is as follows. First, governments simultaneously choose taxes $t^{A}$ and $t^{B}$. Second, the two firms observe the taxes and then simultaneously choose the quantities to be produced for domestic and foreign consumption. That is, the $A$ firm chooses $\left(q^{A H}, q^{A X}\right)$, and the $B$ firm chooses $\left(q^{B H}, q^{B X}\right)$. Third, the players receive their payoffs which are profits $\left(\pi^{A}, \pi^{B}\right)$ for the firms and social welfare $\left(W^{A}, W^{B}\right)$ for the governments. Since this is a game of complete and perfect information, we can use the backward induction method of solving such games. We assume that there are not multiple equilibria in each stage game. Then this method is guaranteed to yield the SPNE (see Kreps, 1989, pp. 421-425 for details).

Suppose that the governments have chosen $t^{A}$ and $t^{B}$. If the 4 tuple $\left(q_{*}^{A H}, q_{*}^{A X}, q_{*}^{B H}, q_{*}^{B X}\right)$ is a Nash equilibrium in the remaining game between the two firms, then it must be true that $\left(q_{*}^{A H}, q_{*}^{A X}\right)$ solve $\max _{\left\{q^{A H}, q^{A X}\right\}} \pi^{A}(\bullet)$, and that $\left(q_{*}^{B H}, q_{*}^{B X}\right)$ solve $\max _{\left\{q^{B H}, q^{B X}\right\}} \pi^{B}(\bullet)$. Now $\pi^{A}=\pi^{A H}+\pi^{A X}$. Thus, the $A$ 
firm's original problem can be written as a pair of optimization problems. In the home market, let $q_{*}^{A H}=\operatorname{argmax}_{q^{A H}}\left\{q^{A H}\left(a-q^{A H}-q_{*}^{B X}-c-t^{A}\right)\right\}$. Then

$$
q_{*}^{A H}=(1 / 2)\left(a-c-q_{*}^{B X}-t^{A}\right) .
$$

In the export market, let $q_{*}^{A X}=\operatorname{argmax}_{q^{A X}}\left\{q^{A X}\left(a-q^{A X}-q_{*}^{B H}-c-t^{A}\right)\right\}$. Then

$$
q_{*}^{A X}=(1 / 2)\left(a-c-q_{*}^{B H}-t^{A}\right) .
$$

In a similar fashion, we can write $\pi^{B}=\pi^{B H}+\pi^{B X}$ for the $B$ firm. Letting $q_{*}^{B H}$ and $q_{*}^{B X}$ be the solutions to the two different $B$ firm optimization problems, we get

$$
q_{*}^{B H}=(1 / 2)\left(a-c-q_{*}^{A X}-t^{B}\right),
$$

and

$$
q_{*}^{B X}=(1 / 2)\left(a-c-q_{*}^{A H}-t^{B}\right) .
$$

Equations (1)-(4) are the reaction functions of the two firms. Solving (1) and (4) simultaneously and (2) and (3) simultaneously, we get

$$
q_{*}^{B H}=q_{*}^{B X}=(1 / 3)\left(a-c-2 t^{B}+t^{A}\right),
$$

and

$$
q_{*}^{A H}=q_{*}^{A X}=(1 / 3)\left(a-c-2 t^{A}+t^{B}\right) .
$$

Equations (5) and (6) represent the equilibrium production levels for the two firms. We now proceed 
to solve the first stage game between the two governments. The two governments will choose taxes to maximize social welfare in their respective countries. Thus, the $i$ th government, $i=A, B$, solves

$$
\max _{t^{i}}(1 / 2)\left(Q^{i}\right)^{2}+\pi^{i}(\bullet)+t^{i}\left(q_{*}^{i H}+q_{*}^{i X}\right)-v^{i}\left(q_{*}^{i H}+q_{*}^{i X}\right) .
$$

The solutions to (7) are

$$
t_{*}^{A}=(1 / 4)\left(2 c-2 a+7 v^{A}-v^{B}\right)
$$

and

$$
t_{*}^{B}=(1 / 4)\left(2 c-2 a+7 v^{B}-v^{A}\right) .
$$

Equations (8) and (9) give us the SPNE taxes for $A$ and $B$ respectively. Since $v^{A}$ is not necessarily equal to $v^{B}$, the two equilibrium taxes are not necessarily equal. The strategic aspect of this Cournot game is clearly captured by the dependence of $t_{*}^{A}$ on $v^{B}$ and the dependence of $t_{*}^{B}$ on $v^{A}$. In the sense of Bulow, Geanakoplos, and Klemperer (1985), each firm treats the output of its competitor as a "strategic substitute." Substituting equations (8) and (9) into equations (5) and (6) gives us the SPNE outcome of this pollution tax game. This outcome is given by equations (8) and (9), $q_{*}^{A H}=q_{*}^{A X}=(1 / 4)\left(2 a-2 c-5 v^{A}+3 v^{B}\right)$, and $q_{*}^{B H}=q_{*}^{B X}=(1 / 4)\left(2 a-2 c+3 v^{A}-5 v^{B}\right)$.

Inspection of equations (8) and (9) is instructive. Let $a>c$, and consider equation (8). We see that when $B$ 's marginal social disutility from pollution is considerably greater than $A$ 's, i.e., when $v^{B}>7 v^{A}$, $A$ will subsidize the production of $q$. On the other hand if $a<c$, then whether or not $A$ will subsidize production depends on the relative magnitudes of the cost and demand parameters $(c, a)$ and the disutility parameters $\left(v^{A}, v^{B}\right)$. 
To determine the effect of the SPNE taxes on consumer surplus, and firm profits in each country, we can substitute the equilibrium values of the four quantities and the two taxes into the corresponding defining functions. First, note that the pre-tax consumer surplus in $B>$ post-tax consumer surplus. ${ }^{8}$ The intuition for this result lies in the fact that for the linear inverse demand function that we have been using, consumer surplus is monotonically increasing in total market output. Second, the post-tax profits for the $B$ firm $\leq$ the pre-tax profits if and only if $\left\{52\left(2 a c-a^{2}-c^{2}\right)\right\} \geq\left\{(12 a-12 c) v^{A}+(276 c-276 a) v^{B}+25\left(v^{A}\right)^{2}+169\left(v^{B}\right)^{2}+130 v^{A} v^{B}\right\}$. We see that the effect of the tax on profits is ambiguous in general. ${ }^{9}$ However, the role of the various model parameters is evident. If the disutility parameters, i.e., $v^{A}$ and $v^{B}$, are much larger than the demand and cost parameters, i.e., $a$ and $c$, then the post-tax profit will exceed the pre-tax profit. On the other hand, if the cost and demand parameters are much larger than the disutility parameters, then the pretax profit will exceed the post-tax profit.

This analysis strengthens the conclusions of Batabyal $(1991,1993)$, and shows that when governments conduct environmental policy in a two stage Cournot game, there exist circumstances in which taxing countries can be worse off. Indeed, consumer surplus in both countries declines unambiguously. A key determinant of the question of being worse off would appear to be the different social disutilities from pollution in the two countries. For instance, since $t^{A}$ is increasing in $v^{A}$ and decreasing in $v^{B}$, and $t^{B}$ is increasing in $v^{B}$ and decreasing in $v^{A}$, significant differences in these parameters can be expected to lead to very different taxes and thence to very

\footnotetext{
${ }^{8}$ While this result is stated for $B$, it should be clear that an analogous result holds for $A$ as well. In the rest of this paper, all results will be stated for $B$ only.

${ }^{9}$ In the rest of this paper, we shall not provide results for the status quo versus post-policy social welfare levels because these results are always ambiguous.
} 
different levels of consumer surplus and firm profits. In concluding this section we note that even when one explicitly incorporates linear functional forms into the analysis, it is not - in general possible to make unqualified statements about the effects of government pollution control policy. However, for both countries, the possibility of being worse off remains.

\section{The Game Model with Caring Government Behavior}

\section{4a. Preliminaries}

In this section we shall analyze the efficacy of alternate pollution control instruments when the government in one country cares about pollution in the second country. The governments in $A$ and $B$ are restricted to choosing between a domestic policy instrument (a production tax), a trade policy instrument (an import tariff), and a combination of these two instruments (the joint policy instrument). Since the underlying issues are now fairly involved, before studying the implications of these three policy instruments, we shall first discuss the issues intuitively.

The first issue concerns world welfare. When there are a number of distortions present in the world economy (these are discussed below) and national governments attempt to correct for these distortions by means of the instruments mentioned above in a non-cooperative game, the ensuing equilibrium is typically optimal in a myopic sense. That is, while individual country welfare is maximized by the respective governments, world welfare is not. In other words, the "correct" taxes and tariffs are those that arise from coordinated play by the respective governments. Practically, this involves coordination of environmental policy by all the players involved. This is something that is not only fairly well understood by analysts but also something that we typically do not observe 
for a variety of well known reasons. ${ }^{10}$ It is worth noting that all the subsequent results are myopic in the sense of this discussion.

In determining which policy instrument to adopt, the government in each country will attempt to weigh the effects of a particular policy on the three distortions that are present in the two country world economy that is being studied. First, there is the pollution distortion. A production tax will reduce pollution by reducing the output of the good which causes pollution. However, this only reduces domestic pollution but does not reduce foreign pollution. An import tariff on the other hand reduces foreign pollution by making the post-tariff purchase of the foreign good undesirable and by increasing the costs of foreign producers. However, since the amount of pollution that is reduced by means of a tariff is probably less than the amount of pollution reduced by means of a production tax, ${ }^{11}$ as far as the pollution distortion is concerned, an optimally set production tax is likely to be the superior policy instrument of the two considered so far. The joint policy instrument would curb both domestic and foreign pollution. Therefore as far as the pollution distortion alone is concerned, of the three instruments under consideration, ex ante, this instrument would appear to be the best means of pollution control.

The second distortion concerns the domestic share of total output. It is very likely that the monopolistic firm in each country does not sell the "correct" amount in the home market. In determining which policy instrument to adopt, the two governments would presumably like to increase the domestic market share of total good production and hence reduce imports. By discouraging the purchase of the foreign good, an import tariff would certainly increase the domestic

\footnotetext{
${ }^{10}$ See Batabyal (1996b) for a discussion of this and related issues.

${ }^{11}$ The actual answer depends on the magnitudes of the relevant parameters.
} 
market share of the total output. A production tax on the other hand would not achieve this goal since a production tax would unambiguously curtail all domestic production. The joint policy instrument can be expected to result in total output which is bounded below by the tax output and above by the tariff output. Thus, as far as this distortion is concerned, ex ante, a tariff would appear to be the best policy instrument.

The third distortion concerns monopoly rents. The second stage game in the model is a game between two monopolists earning excess economic rent. The government in each country would presumably like to capture some of this rent. By collecting some of the revenue which otherwise would go to the foreign monopolist, each government can capture some of the monopoly rent by means of an import tariff. Likewise, a production tax can also transfer some of the surplus collected by the home monopolistic firm to the government setting the tax. The joint policy instrument can also be expected to have the same qualitative impact as a tariff or a tax except that its quantitative impact will certainly be different. Thus as far as this distortion is concerned, all three policy instruments can work in the right direction. The reader should note that in general, the properties of the three instruments are likely to be quite different. We now formally analyze the related questions of the effects of environmental policy and the choice of policy instrument issue in a Cournot game in which governments care about international pollution.

\section{4b. International Environmental Policy with Alternate Control Instruments}

The notation used here is the same as in section 3 except that the tariffs levied by the two countries are now denoted by $r^{A}$ and $r^{B}$ respectively. Let us begin with the general case. In this case, each government controls pollution by means of the joint policy instrument, i.e., an instrument which is a combination of an import tariff and a production tax. Recall that $\pi^{A}=\pi^{A H}+\pi^{A X}$, and 
$\pi^{B}=\pi^{B H}+\pi^{B X}$. On solving these optimization problems, we get four reaction functions. ${ }^{12}$ These are

$$
\begin{gathered}
q_{*}^{A H}=(1 / 3)\left(a-c-2 t^{A}+r^{A}+t^{B}\right), \\
q_{*}^{A X}=(1 / 3)\left(a-c-2 r^{B}-2 t^{A}+t^{B}\right), \\
q_{*}^{B H}=(1 / 3)\left(a-c+r^{B}+t^{A}-2 t^{B}\right),
\end{gathered}
$$

and

$$
q_{*}^{B X}=(1 / 3)\left(a-c+t^{A}-2 r^{A}-2 t^{B}\right) .
$$

Equations (10)-(13) give us the equilibrium quantities which will be produced by the $A$ firm and the $B$ firm in the domestic market and in the export market respectively.

Recall that the $A$ and $B$ governments both care about pollution in the other country. This is modeled by including the $B$ government's disutility from pollution in the $A$ government's objective and vice versa. With this in mind, the first stage of the two stage game can be analyzed. In this stage, the $A$ and $B$ governments solve

$$
\max _{r^{A}, t^{A}}(1 / 2)\left(Q^{A}\right)^{2}+\pi^{A}(\bullet)+\left(t^{A}-v^{A}\right)\left(q_{*}^{A H}+q_{*}^{A X}\right)+\left(r^{A}-v^{B}\right) q_{*}^{B X}-v^{B} q_{*}^{B H},
$$

and

\footnotetext{
${ }^{12}$ In this subsection, we shall solve for most of the equilibrium values of the variables of interest in terms of other endogenous variables and not in terms of the model parameters $a, c, v^{A}$, and $v^{B}$ exclusively. This will facilitate comparison between the three policy instruments under consideration.
} 


$$
\max _{r^{B}, t^{B}}(1 / 2)\left(Q^{B}\right)^{2}+\pi^{B}(\bullet)+\left(t^{B}-v^{B}\right)\left(q_{*}^{B H}+q_{*}^{B X}\right)+\left(r^{B}-v^{A}\right) q_{*}^{A X}-v^{A} q_{*}^{A H} .
$$

respectively. The solutions to problems (14) and (15) are

$$
\begin{gathered}
r_{*}^{A}=(1 / 9)\left(3 a-3 c-3 t_{*}^{B}+7 t_{*}^{A}-3 v^{A}+6 v^{B}\right), \\
t_{*}^{A}=(1 / 7)\left(4 c-4 a+3 r_{*}^{A}-t_{*}^{B}+2 r_{*}^{B}+12 v^{A}-6 v^{B}\right), \\
r_{*}^{B}=(1 / 9)\left(3 a-3 c-3 v^{B}+6 v^{A}+7 t_{*}^{B}-3 t_{*}^{A}\right),
\end{gathered}
$$

and

$$
t_{*}^{B}=(1 / 7)\left(4 c-4 a-t_{*}^{A}+2 r_{*}^{A}+3 r_{*}^{B}-6 v^{A}+12 v^{B}\right) .
$$

Equations (16)-(19) give us the SPNE tariffs and taxes when the two governments care about pollution in each other's country and when they use the joint policy instrument to regulate pollution. Using equations (16)-(19), the four SPNE quantities can be determined. These are

$$
\begin{gathered}
q_{*}^{A H}=(1 / 567)\left(360 a-360 c-108 r_{*}^{A}-9 t_{*}^{B}-27 r_{*}^{B}-873 v^{A}+774 v^{B}-120 t_{*}^{A}\right), \\
q_{*}^{A X}=(1 / 567)\left(171 a-171 c-108 r_{*}^{A}-267 t_{*}^{B}-27 r_{*}^{B}-1062 v^{A}+774 v^{B}+126 t_{*}^{A}\right),
\end{gathered}
$$




$$
q_{*}^{B H}=(1 / 567)\left(360 a-360 c-27 r_{*}^{A}+120 t_{*}^{B}-108 r_{*}^{B}+774 v^{A}-873 v^{B}-9 t_{*}^{A}\right),
$$

and

$$
q_{*}^{B X}=(1 / 567)\left(171 a-171 c-27 r_{*}^{A}+99 t_{*}^{B}-240 t_{*}^{A}-1062 v^{B}+774 v^{A}-108 r_{*}^{B}\right) .
$$

Equations (16)-(23) give us the SPNE outcome of this joint policy instrument game. The reader will note an asymmetry in this SPNE outcome. Inspection of equations (16)-(19) tells us that while the optimal tariffs depend on the endogenous taxes, the optimal taxes depend on the endogenous taxes and the tariffs. This asymmetry will be highlighted even more starkly in the sequel.

We shall now compare the joint policy outcome with the status quo, i.e., the outcome with no government intervention of any kind. For $\operatorname{country} B$, consumer surplus with the joint policy $\leq$ consumer surplus with no intervention as $\left\{r_{*}{ }^{B}+t_{*}^{A}+t_{*}^{B}\right\} \geq 0$. The $B$ firm's profits with the joint policy instrument $\geq$ its profits with no policy as $\left\{2 a r_{*}^{B}+4 a t_{*}^{A}-8 a t_{*}^{B}-4 a r_{*}^{A}-2 c r_{*}^{B}-4 c t_{*}^{A}+8 c t_{*}^{B}+4 c r_{*}^{A}-\right.$ $\left.4 r_{*}^{B} t_{*}^{B}-8 t_{*}^{A} t_{*}^{B}+8\left(t_{*}^{B}\right)^{2}+\left(r_{*}^{B}\right)^{2}+8 r_{*}^{A} t_{*}^{B}+2 r_{*}^{B} t_{*}^{A}-4 r_{*}^{A} t_{*}^{A}+4\left(r_{*}^{A}\right)^{2}+2\left(t_{*}^{A}\right)^{2}\right\} \geq 0$. While consumer surplus with the joint policy declines as long as the sum of $r_{*}^{B}, t_{*}^{A}$, and $t_{*}^{B}$ is positive, the profits comparison is ambiguous. Because of this ambiguity and to facilitate a comparison of the implications of alternate forms of pollution control, we now consider two special cases of the above general case. In the first case, the two governments play a Cournot tariff game. In this scenario, the only pollution control instrument available to the two governments is an import tariff. In the second case, the two governments play a Cournot tax game. In this latter scenario, the sole pollution control instrument available to the $A$ and the $B$ governments is a production tax. 


\section{4b1. The tariff only game}

The SPNE outcome of the Cournot tariff game can be determined by substituting $t^{A}=t^{B}=0$ in equations (10)-(13), (16), and (18). This yields

$$
\begin{gathered}
r_{*}^{A}=(1 / 3)\left(a-c-v^{A}+2 v^{B}\right), \\
r_{*}^{B}=(1 / 3)\left(a-c-v^{B}+2 v^{A}\right), \\
q_{*}^{A H}=(1 / 9)\left(4 a-4 c-v^{A}+2 v^{B}\right), \\
q_{*}^{A X}=(1 / 9)\left(a-c+2 v^{B}-4 v^{A}\right), \\
q_{*}^{B H}=(1 / 9)\left(4 a-4 c-v^{B}+2 v^{A}\right),
\end{gathered}
$$

and

$$
q_{*}^{B X}=(1 / 9)\left(a-c+2 v^{A}-4 v^{B}\right) .
$$

Straightforward computation reveals that the status quo consumer surplus in $B>$ the post-tariff consumer surplus. Further, the $B$ firm's post-tariff profits $\leq$ the status quo level of profits if and only if $\left\{4 a r_{*}^{A}+2 c r_{*}^{B}\right\} \geq\left\{4\left(r_{*}^{A}\right)^{2}+\left(r_{*}^{B}\right)^{2}+4 c r_{*}^{A}+2 a r_{*}^{B}\right\}$.

\section{4b2. The tax only game}

In similar fashion, the SPNE outcome of the Cournot tax game can be determined by 
substituting $r^{A}=r^{B}=0$ in equations (10)-(13), (17), and (19). This yields

$$
\begin{gathered}
t_{*}^{A}=(1 / 7)\left(4 c-4 a-t_{*}^{B}+12 v^{A}-6 v^{B}\right), \\
t_{*}^{B}=(1 / 7)\left(4 c-4 a-t_{*}^{A}-6 v^{A}+12 v^{B}\right), \\
q_{*}^{A H}=q_{*}^{A X}=(1 / 21)\left(11 a-11 c+24 v^{B}-30 v^{A}-t_{*}^{A}+2 t_{*}^{B}\right),
\end{gathered}
$$

and

$$
q_{*}^{B H}=q_{*}^{B X}=(1 / 21)\left(11 a-11 c+24 v^{A}-30 v^{B}-t_{*}^{B}+2 t_{*}^{A}\right) .
$$

Comparing the outcome of this tax game to the status quo outcome, it is straightforward to verify that the post-tax consumer surplus $<$ the status quo consumer surplus. Further, the post-tax $B$ firm's profits $\leq$ the status quo profits if and only if $\left\{4 a t_{*}^{B}+2 c t_{*}^{A}+4 t_{*}^{A} t_{*}^{B}\right\} \geq\left\{a t_{*}^{A}+4\left(t_{*}^{B}\right)^{2}+4 c t_{*}^{B}+\right.$ $\left.2 a t_{*}^{A}\right\}$.

\section{4b3. A comparative analysis of the three policy instruments}

Comparing the equilibrium tariff in the tariff only game with the equilibrium tax in the tax only game, we see that with respect to the status quo in $B$, the tariff (tax) increases consumer surplus provided that $r_{*}^{B}<(>)\left\{t_{*}^{A}+t_{*}^{B}\right\}$, and increases the firm's profits provided that $\left\{4\left(r_{*}^{A}\right)^{2}+\left(r_{*}^{B}\right)^{2}+2(c-a)\left(2 r_{*}^{A}-r_{*}^{B}\right)\right\}>(<)\left\{2\left(t_{*}^{A}\right)^{2}+8\left(t_{*}^{B}\right)^{2}+4(c-a)\left(2 t_{*}^{B}-t_{*}^{A}\right)-8 t_{*}^{A} t_{*}^{B}\right\}$.

Similarly, comparing the outcome of the joint policy game with the tariff only game, we see that consumer surplus in $B$ with the joint policy instrument $\leq$ consumer surplus with the tariff as 
$\left\{r_{*}^{B}+t_{*}^{A}+t_{*}^{B}\right\}^{\text {Joint Policy }} \geq\left\{r_{*}^{B}\right\}^{\text {Tariff }}$. Further, the $B$ firm's profits with the joint policy instrument $\geq$ profits with the tariff as $\left\{2 a r_{*}^{B}+4 a t_{*}^{A}-8 a t_{*}^{B}-4 a r_{*}^{A}-2 c r_{*}^{B}-4 c t_{*}^{A}+8 c t_{*}^{B}+4 c r_{*}^{A}-4 r_{*}^{B} t_{*}^{B}-8 t_{*}^{A} t_{*}^{B}+8\left(t_{*}^{B}\right)^{2}\right.$ $\left.+8 r_{*}^{A} t_{*}^{B}+2 r_{*}^{B} t_{*}^{A}-4 r_{*}^{A} t_{*}^{A}+2\left(t_{*}^{A}\right)^{2}\right\}^{\text {Joint Policy }} \geq\left\{4\left(r_{*}^{A}\right)^{2}+\left(r_{*}^{B}\right)^{2}+4 c r_{*}^{A}-4 a r_{*}^{A}+2 a r_{*}^{B}-2 c r_{*}^{B}\right\}^{\text {Tariff. }}$.

Finally, comparing the outcome in the tax only game to the outcome in the joint policy game, we see that consumer surplus in $B$ with the joint policy $\leq$ consumer surplus with the tax as $\left\{r_{*}^{B}+t_{*}^{A}+t_{*}^{B}\right\}^{\text {Joint Policy }} \geq\left\{t_{*}^{A}+t_{*}^{B}\right\}^{\text {Tax }}$. The $B$ firm's profits with the joint policy $\geq$ its profits with a tax as $\quad\left\{2 a r_{*}^{B}+4 a t_{*}^{A}-8 a t_{*}^{B}-4 a r_{*}^{A}-2 c r_{*}^{B}-4 c t_{*}^{A}+8 c t_{*}^{B}+4 c r_{*}^{A}-4 r_{*}^{B} t_{*}^{B}-8 t_{*}^{A} t_{*}^{B}+8\left(t_{*}^{B}\right)^{2}+8 r_{*}^{A} t_{*}^{B}+\left(r_{*}^{B}\right)^{2}+\right.$ $\left.2 r_{*}^{B} t_{*}^{A}-4 r_{*}^{A} t_{*}^{A}+4\left(r_{*}^{A}\right)^{2}+2\left(t_{*}^{A}\right)^{2}\right\}^{\text {Joint Policy }} \geq\left\{2\left(t_{*}^{A}\right)^{2}-8 a t_{*}^{B}+8\left(t_{*}^{B}\right)^{2}+8 c t_{*}^{B}-4 c t_{*}^{A}+4 a t_{*}^{A}-8 t_{*}^{A} t_{*}^{B}\right\}^{\text {Tax }}$.

An initial examination of the above results suggests that the choice of instrument issue is hopelessly tangled. However, a few insights can be gained by performing numerical analyses of this

\section{Table 1 about here}

issue. Table 1 presents the results of two such case studies..$^{13}$ These results use the conditions identified in the previous three paragraphs. First, we see that the results are quite sensitive to the specific values assigned to the relevant parameters and the variables. Second, consumers will in general prefer the tariff or the tax to the joint policy instrument. This is because in neither of the two cases analyzed does the joint policy instrument have a desirable positive effect on consumer surplus. Third, consumers and the firm can be expected to have opposite preferences as far as the question of instrument choice is concerned. This stems from the fact that in five of the six pairwise comparisons, the instrument which has a greater positive impact on consumer surplus does not also have a similar impact on firm profits.

\footnotetext{
${ }^{13}$ The values assigned to the various parameters and variables in Table 1 are purely for illustrative purposes.
} 
A comparison of equations (24) and (25) with equations (30) and (31) shows that while the equilibrium tariffs in the tariff only game constitute dominant strategies for the two governments, such is not the case for the equilibrium strategies in the tax only and joint policy games. In other words, in the special case in which governments do not levy production taxes, choosing tariffs given by equations (24) and (25) constitute dominant strategies for the $A$ and $B$ governments. That is, optimal tariff setting by one government does not require knowledge of the tariff set by the second government. In general, one cannot expect countries to be able to choose which Cournot game they will play. However, this analysis suggests that the lower informational requirements of optimal tariff setting can provide a rationale for protection.

In every comparative exercise that we have undertaken, the intuition for the consumer surplus result lies in recognizing that consumer surplus is monotonically increasing in total output. Consequently, any government policy which reduces total output below the status quo level of output will necessarily reduce consumer surplus.

When the instrument choice question is restricted to one between the tariff and the tax, we see that when $r_{*}^{B}=t_{*}^{A}+t_{*}^{B}$, consumers in $B$ are indifferent between a tariff and a tax because both instruments produce identical changes in their surplus. Now consider the reference point in which $r_{*}^{B}<t_{*}^{A}+t_{*}^{B}$. This is a situation where consumers are better off with a tariff. This tariff, say $\bar{r}_{*}^{B}$, is clearly less than $r_{*}^{B}=t_{*}^{A}+t_{*}^{B}$. Thus the tariff which makes consumers better off is lower than the tariff which makes consumers indifferent. The government's preferences - as far as tariff or tax is concerned - will depend on which instrument leads to higher social welfare. Now view this question from the tax perspective. At the point of indifference $t_{*}^{B}=r_{*}^{B}-t_{*}^{A}$. With the tax, consumers in $B$ are better off when $r_{*}^{B}>t_{*}^{A}+t_{*}^{B}$, which implies that like the tariff case, the tax which makes consumers in $B$ better 
off is smaller than the tax which makes them indifferent. ${ }^{14}$ In this last case, the $B$ firm can be expected to be opposed to the tax and the $A$ firm can be expected to be in favor of the tax.

Of the three instruments under consideration, the informational requirements of the joint policy instrument are the greatest. For instance, from equations (16)-(19), we see that in order to set $r_{*}^{B}$ and $t_{*}^{B}$, the $B$ government must know $t_{*}^{A}$ and $r_{*}^{A}$ and $t_{*}^{A}$ respectively. While the joint policy instrument is probabally the most desirable in terms of correcting the different distortions alluded to in section $4 \mathrm{a}$, given its informational requirements, its implementation is likely to be rather costly. This completes our discussion of the instrument choice question.

\section{Conclusions}

In this paper, a strategic analysis of two important issues concerning optimal environmental policy in an open economy was undertaken. We first explored the effects of conducting environmental policy in a two stage Cournot game. It was shown that when governments interact strategically, there are theoretical circumstances in which the conduct of environmental policy can make a nation worse off. This finding is a possible explanation as to why governments are often loath to conduct environmental policy even when the incidence of pollution is domestic.

Next, we studied the issue of "prices versus prices," i.e., the implications of pollution regulation by means of alternate price control instruments when national governments care about government behavior and thence pollution in other countries. Our numerical analysis showed that it is not possible to resolve the instrument choice issue unambiguously. Nevertheless, we identified several inequalities which determine whether consumers and producers are likely to gain or lose

\footnotetext{
${ }^{14}$ This discussion assumes that the $B$ tax is positive.
} 
from the pursuit of a specific policy. As we discussed, a basic issue faced by the two governments concerns the tradeoff between policy efficacy on the one hand and the cost of policy implementation on the other.

The analysis of this paper can be extended in a number of directions. With some adjustments, our model can be used to study the fractious agricultural/environmental policy formation process between trading entities such as the USA and the EC. Second, this model can also help us understand why the policy response in large developing countries to environmental externalities has been slow if not altogether non-existent. Finally, this paper's analysis can be made richer by making the models truly dynamic and by explicitly incorporating uncertainty into the decision making process. This will enable one to analyze issues related to threats and punishments, governmental reputation, and long run policy formation. 


\begin{tabular}{|c|c|c|c|}
\hline \multicolumn{4}{|c|}{ Table 1} \\
\hline \multicolumn{4}{|c|}{$\begin{array}{l}\text { A Numerical Analysis of the Effects of the Three Policy Instruments on Consumer Surplus } \\
\qquad \text { and on Firm Profits in } B\end{array}$} \\
\hline Variable of Interest & Tariff versus Tax & $\begin{array}{c}\text { Joint Policy } \\
\text { Instrument versus } \\
\text { Tariff } \\
\end{array}$ & $\begin{array}{c}\text { Joint Policy } \\
\text { Instrument versus } \\
\text { Tax } \\
\end{array}$ \\
\hline \multicolumn{4}{|c|}{ Case I: $a=c, r_{*}^{A}=3, r_{*}^{B}=4, t_{*}^{A}=5, t_{*}^{B}=6$} \\
\hline Consumer Surplus & Higher with tariff & Higher with tariff & Higher with tax \\
\hline Firm Profits & Higher with tax & $\begin{array}{l}\text { Higher with joint } \\
\text { policy instrument }\end{array}$ & $\begin{array}{l}\text { Higher with joint } \\
\text { policy instrument }\end{array}$ \\
\hline \multicolumn{4}{|c|}{ Case II: $a=c, r_{*}^{A}=7, r_{*}^{B}=9, t_{*}^{A}=3, t_{*}^{B}=5$} \\
\hline Consumer Surplus & Higher with tax & Higher with tariff & Higher with tax \\
\hline Firm Profits & Higher with tariff & Higher with tariff & $\begin{array}{l}\text { Higher with joint } \\
\text { policy instrument }\end{array}$ \\
\hline
\end{tabular}




\section{References}

Asako, K., (1979), "Environmental Pollution in an Open Economy," Economic Record, Vol. 55, pp. 359-367.

Batabyal, A. A., (1991), "Environmental Pollution and Unilateral Control in an Open Economy," Natural Resource Modeling, Vol. 5, pp. 445-467.

Batabyal, A. A., (1993), "Should Large Developing Countries Pursue Environmental Policy Unilaterally?” Indian Economic Review, Vol. 28, pp. 191-202.

Batabyal, A. A., (1996a), "Game Models of Environmental Policy in an Open Economy," Annals of Regional Science, Vol. 30, pp. 185-200.

Batabyal, A. A., (1996b), "Development, Trade, and the Environment: Which Way Now?" Ecological Economics, Vol. 13, pp. 83-88.

Behr, P., (1994), “U. S., Canada Settle Fight Over Wheat," The Washington Post, August 2, pp. D1, D4.

Bulow, J., Geanakoplos, J. D., and Klemperer, P. D., (1985), “Multimarket Oligopoly: Strategic Substitutes and Complements," Journal of Political Economy, Vol. 93, pp. 488-511.

Conrad, K., and Schroder, M. (1991), “Controlling Air Pollution: The Effects of Alternative Approaches," in Siebert, H., (Ed.), Environmental Scarcity: The International Dimension. Tubingen: J. C. B. Mohr.

Dockner, E. J., and Long, N. V., (1993), “International Pollution Control: Cooperative versus NonCooperative Strategies," Journal of Environmental Economics and Management, Vol. 25, pp. 13-29.

Kreps, D. M., (1989) A Course in Microeconomic Theory. Princeton, NJ: Princeton University Press. 
Leidy, M. P., and Hoekman, B. M., (1994), “'Cleaning up' while Cleaning Up? Pollution Abatement, Interest Groups and Contingent Trade Policies," Public Choice, Vol. 78, pp. 241258

Markusen, J. R., (1975), "International Externalities and Optimal Tax Structures," Journal of International Economics, Vol. 5, pp. 15-29.

Merrifield, J. D., (1988), “The Impact of Selected Abatement Strategies on Transnational Pollution, the Terms of Trade, and Factor Rewards: A General Equilibrium Approach," Journal of Environmental Economics and Management, Vol. 15, pp. 259-284.

Morkre, M. E., and Kruth, H. E., (1989), "Determining Whether Dumped or Subsidized Imports Injure Domestic Industries," Contemporary Policy Issues, Vol. 7, pp. 78-95.

Pethig, R., (1976), "Pollution, Welfare and Environmental Policy in the Theory of Comparative Advantage," Journal of Environmental Economics and Management, Vol. 2, pp. 160-169.

Siebert, H., Eichberger, J., Gronych, R., and Pethig, R., (1980), Trade and Environment: A Theoretical Enquiry. Amsterdam: Elsevier Publishing Company.

Simone, M., (1994), "U. S. And Canada: The Nature of Ag Trade Disputes," Agricultural Outlook, AO-210, August, pp. 28-31.

Ulph, A. M., (1992), "The Choice of Environmental Policy Instruments and Strategic International Trade," in Pethig, R., (Ed.), Conflicts and Cooperation in Managing Environmental Resources. Berlin: Springer-Verlag. 


\title{
POLICY IN AN OPEN ECONOMY
}

\author{
by
}

\author{
AMITRAJEET A. BATABYAL \\ Department of Economics \\ Utah State University \\ Logan, UT 84322-3530 \\ USA \\ Tel: (801) 797-2314 \\ Fax: (801) 797-2701 \\ Internet: Batabyal@b202.usu.edu
}

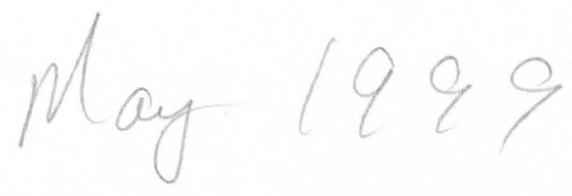




\begin{abstract}
In this paper we study some of the consequences of national environmental policy in a strategic international setting. Two broad questions are analyzed. First, we examine the circumstances under which the pursuit of environmental policy by a country in a Cournot game, will make that country worse off when the incidence of pollution is domestic. Second, we study the effects of environmental regulation by means of alternate price control instruments in a Cournot game in which national governments care about international pollution, but polluting firms do not.

It is shown that there are plausible theoretical circumstances in which the pursuit of environmental policy in a strategic setting is not necessarily a desirable objective. Further, it is shown that in choosing between alternate pollution control instruments, national governments typically face a tradeoff between instruments which correct more distortions but are costly to implement and instruments which correct fewer distortions and are less costly to implement. In particular, a dominance result for a tariff policy is obtained; this result favors protection, i.e., the use of tariffs, from an informational standpoint alone.
\end{abstract}

Keywords: Environmental policy, Cournot game, government, trade JEL Classification: D62, F13, Q28 